\title{
Description of a multicenter safety checklist for intraoperative hemorrhage control while clamped during robotic partial nephrectomy
}

\author{
Kenneth G Nepple', Gurdarshan S Sandhu', Craig G Rogers², Mohamad E Allaf ${ }^{3}$, Jihad H Kaouk4,
} Robert S Figenshau ${ }^{1}$, Michael D Stifelman ${ }^{5}$ and Sam B Bhayani ${ }^{1,6^{*}}$

\begin{abstract}
Background: The adoption of robotic assistance has contributed to the increased utilization of partial nephrectomy for the management of renal tumors. However, partial nephrectomy can be technically challenging because of intraoperative hemorrhage, which limits the ability to identify the tumor margin and may necessitate the conversion to open surgery or radical nephrectomy. To our knowledge, a comprehensive safety checklist does not exist to guide surgeons on the management of hemorrhage during robotic partial nephrectomy. We developed such an safety checklist based on the cumulative experiences of high volume robotic surgeons.

Methods: A treatment safety checklist for the management of hemorrhage during robotic partial nephrectomy was collaboratively developed based on prior experiences with intraoperative hemorrhage during robotic partial nephrectomy.

Results: Reducing the risk of hemorrhage during robotic partial nephrectomy begins with reviewing the preoperative imaging for renal vasculature and tumor anatomy, with a focus on accessory vessels and renal tumor proximity to the renal hilum. During hilar exposure, an attempt is made to identify additional accessory renal arteries. The decision is then made on whether to clamp the hilum (artery +/- vein). If bleeding is encountered during resection, management is based on whether the bleeding is suspected to be arterial or from venous backbleeding. Operative maneuvers that may increase the chance of success are highlighted in safety checklists for arterial and venous bleeding.

Conclusions: Safely performing robotic partial nephrectomy is dependent on attention to prevention of hemorrhage and rapid response to the challenge of intraoperative bleeding. Preparation is essential for maximizing the chance of success during robotic partial nephrectomy.
\end{abstract}

Keywords: Kidney neoplasms, Robotics, Nephrectomy, Hemorrhage, Patient safety

\section{Introduction}

Hemorrhage during surgery is a patient safety concern and a source of stress for surgeons. During partial nephrectomy, in which part of the kidney is removed for a renal tumor, hemorrhage can be particularly troublesome because the kidney is a well perfused organ and renal cell carcinomas are associated with increased vascularity [1]. Traditionally, partial nephrectomy had been

\footnotetext{
* Correspondence: bhayani@wustl.edu

'Washington University School of Medicine, St. Louis, MO, USA

Full list of author information is available at the end of the article
}

performed via an open approach but there has been a steady trend toward a minimally invasive approach [2].

As partial nephrectomy is increasingly performed with a minimally invasive approach, control of intraoperative hemorrhage can be more challenging than simple manual compression of the renal parenchyma with suturing, as can be done in open surgery. Hemorrhage is further concerning as control can occupy valuable time during which the renal unit is ischemic due to renal vascular clamping during tumor excision. The surgeon is essentially "on the clock" to unclamp the renal unit as soon as possible to prevent acute tubular necrosis and further 
loss of renal function. During this stressful situation, it is imperative for the surgeon to have an organized approach to management of hemorrhage, as delayed management could lead to prolonged ischemic times, iatrogenic positive surgical margins from inadequate visualization, conversion to open surgery, or radical nephrectomy.

Series on robotic partial nephrectomy report a reasonable blood loss (Table 1). Nevertheless, the specific situation of "bleeding while clamped" is likely underreported. Experts who publish their results may seamlessly manage this issue without adverse events, and thereby avoid complications in their published series. Thus, the existing literature does little to educate surgeons on how to deal with bleeding during robotic partial nephrectomy while clamped.

The goal of this manuscript is to educate robotic surgeons in factors to minimize hemorrhage during robotic partial nephrectomy. We identified factors to consider during review of preoperative imaging and renal hilar exposure. We then developed a safety and management checklist for "hemorrhage while clamped" during robotic partial nephrectomy.

\section{Methods}

Robotic partial nephrectomy was initially reported in 2004 [19]. Since that time, the authors have performed a total of over 1500 robotic partial nephrectomies. During educational courses on robotic urological surgery from 2007 to 2010, it was noted that comments were made regarding management of hemorrhage during robotic partial nephrectomy. Suggestions for management were made from audience members, experts, and other attendees of the courses. However, starting in 2011, there were no new suggestions or options, suggesting "saturation" of management options. Based on these comments, a safety checklist with the mentioned options for managing hemorrhage was constructed for educational purposes by two of the authors (KN and $\mathrm{SB}$ ) and then revised based on comments from the multi-institutional group of authors.

\section{Results}

\section{Preoperative imaging}

Avoiding hemorrhage during robotic partial nephrectomy begins with review of the preoperative imaging, which for renal tumors typically includes CT or MRI with contrast. The imaging should be reviewed carefully, in axial and coronal planes, for the presence of accessory renal arteries which may be identified in greater than $20 \%$ of cases [20]. Accessory renal arteries become important because if such an artery is not occluded during hilar clamping, then substantial arterial bleeding can occur during tumor resection. Tumor size and vicinity to renal hilar vessels is also inspected on preoperative imaging, as larger and more central tumors have an increased risk of hemorrhage [21].

\section{Renal hilar dissection and clamping}

Prior to renal tumor dissection, the renal hilum (renal artery and vein) is exposed. Surgical dissection should proceed slowly to avoid inadvertent vascular injury and

Table 1 Selected reports from 2009-2012 of estimated blood loss during robotic partial nephrectomy with hilar clamping.

\begin{tabular}{|c|c|c|c|c|}
\hline Reference & Year & $\begin{array}{l}\text { Series } \\
\text { size }\end{array}$ & Estimated blood loss (mean or median) & Estimated blood loss (range) \\
\hline Ficarra et al [3] & 2012 & 347 & 100 (median) & $50-150$ (IQR) \\
\hline Castillo et al[4] & 2012 & 25 & 440 (mean) & 20-2000 (range) \\
\hline Dulabon et al[5] & 2011 & 446 & 262 for hilar vs. 208 for nonhilar $(p=0.14)$ (mean) & 50-1250 for hilar, 0-2200 for nonhilar (range) \\
\hline Naeem et al[6] & 2011 & 97 & 150 for obese vs. 100 for nonobese $(p=0.03)$ (mean) & 75-250 for obese, 50-150 for nonobese (IQR) \\
\hline Kaouk et al[7] & 2011 & 252 & 332 for initial vs. 248 for contemporary ( $p=0.04$ ) (mean) & $\begin{array}{l}\text { 50-1400 for initial, 10-2200 for contemporary } \\
\text { (range) }\end{array}$ \\
\hline Lorenzo et al[8] & 2011 & 65 & 243 (mean) & 0-1600 (range) \\
\hline Williams et al[9] & 2011 & 27 & 180 (mean) & NA \\
\hline Petros et al[10] & 2011 & 95 & $\begin{array}{l}150 \text { if prior surgery vs. } 100 \text { if no prior surgery }(p=0.14) \\
\text { (mean) }\end{array}$ & $\begin{array}{l}69-250 \text { if prior surgery, } 50-200 \text { if no prior surgery } \\
(\mathrm{IQR})\end{array}$ \\
\hline Gong et al[11] & 2010 & 29 & 220 (mean) & $100-370$ (range) \\
\hline Patel et al[12] & 2010 & 71 & 100 for $\leq 4 \mathrm{~cm}$ vs. 100 for $>4 \mathrm{~cm}(p=0.29)$ (median) & 75-200 for $\leq 4 \mathrm{~cm}$ vs. 50-200 for $>4 \mathrm{~cm}$ (IQR) \\
\hline Benway et al[13] & 2010 & 183 & 132 (mean) & 10-900 (range) \\
\hline Scoll et al[14] & 2010 & 100 & 127 (mean) & $50-800$ (range) \\
\hline Benway et al[15] & 2009 & 50 & 140 (mean) & 25-450 (range) \\
\hline Benway et al[16] & 2009 & 129 & 155 (mean) & $\mathrm{NA}$ \\
\hline Ho et al[17] & 2009 & 20 & 189 (mean) & 50-260 (range) \\
\hline
\end{tabular}

Adapted from Benway et al.[18] (IQR = Interquartile range, NA = Not available) 
blood loss during this portion of the procedure, and it is useful to have vascular suture (i.e. 4-0 Prolene on an RB-1 needle anchored with a LAPRA-TY clip) available for vascular suturing if necessary to control venous bleeding. An accessory renal artery is sometimes identified which was not visualized on preoperative imaging. Further delineation of renal arterial anatomy (to identify accessory renal arteries or confirm adequate clamping) may be assisted by the use of a laparoscopic Doppler ultrasound probe [22] or near infrared fluorescence of intravenous indocyanine green [23]. Even in cases where there is only one renal artery, the surgeon must be mindful of clamping the renal artery after it has already branched. If arterial clamping is performed too distally, an unoccluded proximal renal artery branch supplying the tumor itself can result in significant arterial bleeding during resection.

In the case of tumors of increased complexity (hilar tumors, endophytic, larger tumors), additional dissection can be considered to improve hilar exposure. Additional dissection to consider include: extra dissection of the renal hilar vessels proximally and distally, ligation of the gonadal vein to improve exposure, or dissection of the adrenal gland away from the kidney. These measures may improve hilar access if needed for subsequent clamping with a laparoscopic Satinsky clamp or use of a stapler if conversion to radical nephrectomy is required.

Once the hilar anatomy is delineated and the tumor is exposed, the decision is then made on how to perform hilar clamping. Available methods of hilar clamping include assistant-placed laparoscopic vascular clamps, robotic surgeon-placed clamps, or placement of a laparoscopic Satinsky clamp. The correct choice of clamp is based primarily on surgeon preference. If the Satinsky clamp is placed then an additional assistant port must be placed and care must be taken to avoid a collision between a robotic arm and the clamp, which could potentially lead to avulsion of the hilum and significant hemorrhage.

Following renal hilar and tumor exposure, a decision is then made to clamp the artery alone or to clamp both the artery and the vein. For small, exophytic renal tumors, clamping of the artery alone is typically sufficient. However, for tumors that are more endophytic, the possibility of encountering a sizable venous branch during excision is increased and therefore clamping of the renal vein should also be considered.

\section{Bleeding source during tumor resection: arterial versus venous}

All suggestions for intraoperative management of hemorrhage during robotic partial nephrectomy involved identification if the hemorrhage was arterial or venous in origin, as management options differed depending on this critical branch point. Several clues may help the surgeon identify whether the bleeding source is arterial or venous. Arterial bleeding is pulsatile and typically of a larger volume while venous bleeding may generally be more of an ooze and of a lower volume. In additional to the initial assessment of bleeding as arterial versus venous, communication should also occur with anesthesia to alert them to the possibility of hemodynamic instability from hemorrhage so that appropriate support with intravenous fluid and blood transfusion may be given as needed.

\section{Arterial bleeding}

The arterial safety checklist (Figure 1) addresses management of arterial bleeding from the partial nephrectomy bed. Often more than one of these maneuvers may be needed. Two suggestions involve adjunct measures, which despite not directly controlling the arterial bleeding may nonetheless help to decrease the amount of hemorrhage and allow for the opportunity to identify the arterial source of bleeding. First, if the patient is hypertensive, then controlled reduction of blood pressure by anesthesia may improve visualization. A second temporizing option is to unclamp the renal vein. This option at times may substantially improve visualization by allowing venous outflow in the setting of continued arterial inflow into the partial nephrectomy bed.

Further suggestions for the management of arterial bleeding focus on methods to control the actual renal arterial branch which is the source of the bleeding. These include placement of an additional clamp for arterial control, either on the same artery if there is inadequate clamp pressure or on an accessory artery if one is identified with further dissection.

Even with the aforementioned efforts, arterial bleeding may persist. If this bleeding persists at a manageable level, then excision of the renal mass can continue expediently with consideration of adjunct measures to control bleeding such as tamponade of the bleeding (by placement of pressure by the surgical assistant with suction device or other instrument) or by placement of a suture at the resection bed even if the mass has only been partially excised. Once the mass is excised then further hemostatic measures can be performed including cauterizing the base of the resection bed, suturing the resection bed, and placing sliding clip renorrhaphy sutures [15] ultimately providing compression of the parenchyma. However, if bleeding is not manageable, then importantly, emergent open conversion (for open partial nephrectomy or complete nephrectomy) or robotic nephrectomy may be necessary.

\section{Venous backbleeding}

The management safety checklist of venous hemorrhage (Figure 2) is generally technically easier to manage than 


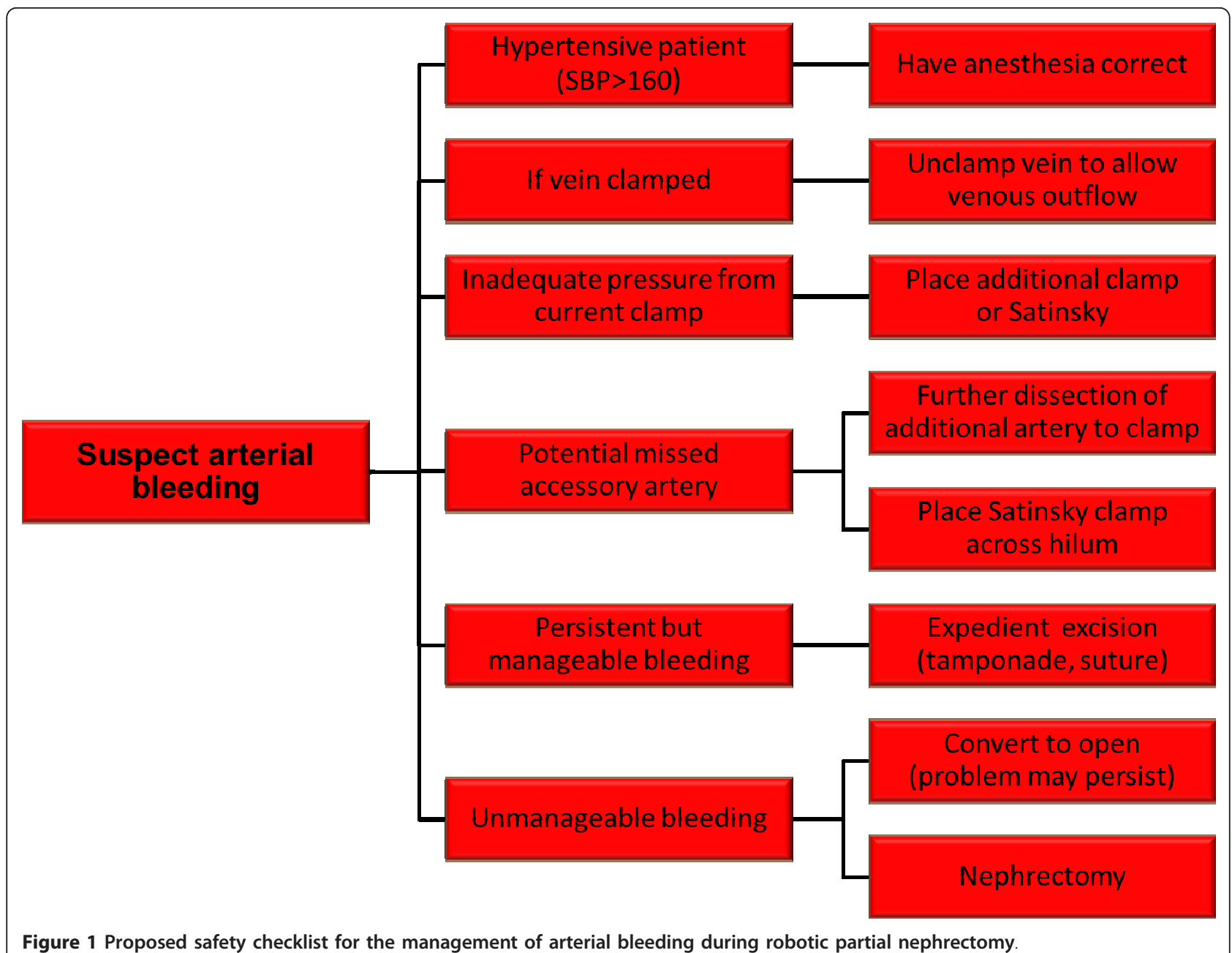

arterial bleeding. The insufflation pressure maintaining the pneumoperitoneum can be increased up to $18 \mathrm{~mm}$ $\mathrm{Hg}$ to improve visualization. This measure is typically well tolerated by most patients, although anesthesia should be informed of the need to monitor for increases in end tidal carbon dioxide or difficulty with ventilation. The theoretical increased risk of gas embolism with increased pneumoperitoneum pressures has been hypothesized [24], but the authors are not aware of the actual occurrence [25].

In contrast to vein unclamping with arterial bleeding, with venous bleeding an additional clamp can be placed on the renal vein to decrease venous backbleeding. Additionally, on the left side placement of the clamp on the renal vein lateral to the gonadal and adrenal veins may stop additional backbleeding from those branches. In practice, the tumor can often be excised despite venous hemorrhage which can subsequently be controlled with suturing the tumor bed. Conversion to open surgery for radical nephrectomy for venous bleeding during minimally invasive partial nephrectomy is uncommon $[26,27]$.

\section{Discussion}

Hemorrhage during robotic partial nephrectomy is probably underreported, as most series are reported by high volume surgeons at tertiary care centers who may not have major consequences from this bleeding. Therefore, hemorrhage may not result in a formal complication if it is quickly and efficiently controlled. Nevertheless, as hemorrhage may occur during critical and often stressful portions of the operation, an array of management options should be recognized by the surgeon performing the procedure. We present a comprehensive discussion of factors to consider regarding hemorrhage during robotic partial nephrectomy. It is our hope that review of these factors will educate other surgeons in preparation for this experience, and thus increases patient safety and surgeon confidence in dealing with this difficult situation. 


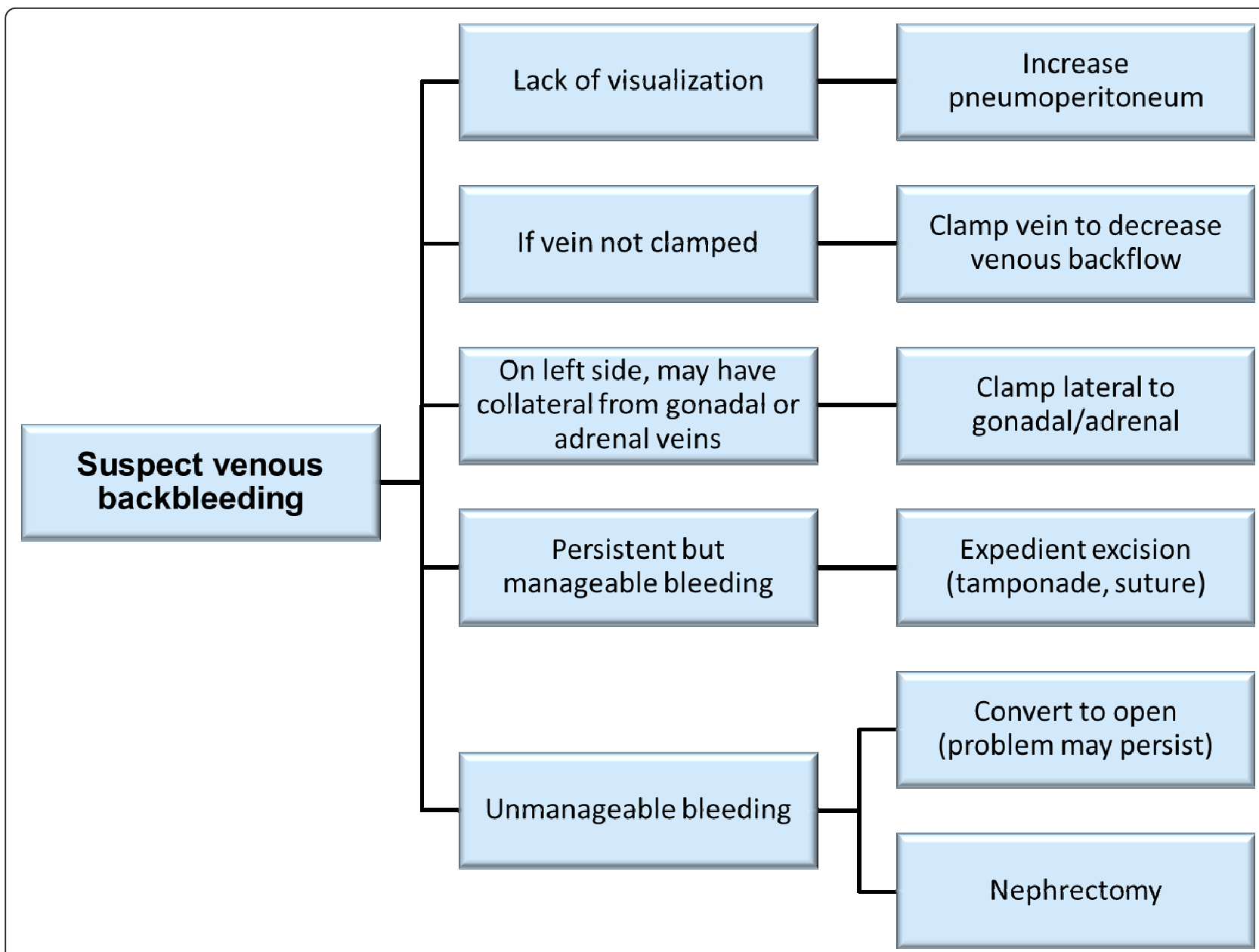

Figure 2 Proposed safety checklist for the management of venous backbleeding during robotic partial nephrectomy.

In practice, hemorrhage prevention may be more important that hemorrhage management. Hemorrhage can be prevented quite simply with accurate identification of all arteries and veins, and use of adequately functioning vascular clamps. Unfortunately, such a statement presumes that the surgeon ability, radiographic imaging, and patient anatomy are uniform, easily identified, and subject to no variability. In "real world" situations, all of our high volume experts have dealt with hemorrhage during partial nephrectomy while clamped and thus have contributed to the discussion of options.

The safety checklists present an array of options, however good clinical judgment remains paramount. For example, a surgeon may not improve hemostasis by implementing measures for venous hemorrhage in a patient that actually has arterial hemorrhage instead. Additionally, as the brisk bleeding with arterial hemorrhage can be difficult to manage and can result in rapid patient instability, the decision to eventually convert to an open procedure or radical nephrectomy to allow for safe completion of the surgery is ultimately based on sound clinical acumen which guides the surgeon through their organized approach to such a scenario.

On an educational and safety level, knowledge of the potential options for hemorrhage management may prevent worsening of conditions, particularly amongst lower volume surgeons. Although testing such safety checklists is impossible, discussion of the management of hemorrhage is important to disseminate in the literature in an effort to potentially improve patient safety.

\section{Conclusions}

Safely performing robotic partial nephrectomy is dependent on attention to prevention of hemorrhage and rapid response to the challenge of intraoperative bleeding. Preparation is essential for maximizing the chance of success during robotic partial nephrectomy.

\section{Author details}

'Washington University School of Medicine, St. Louis, MO, USA. ${ }^{2}$ Henry Ford Hospital, Detroit, MI, USA. ${ }^{3}$ Johns Hopkins University, Baltimore, MD, USA.

${ }^{4}$ Cleveland Clinic, Cleveland, OH, USA. ${ }^{5}$ New York University School of 
Medicine, New York, NY, USA. 'Department of Surgery, Division of Urology, Washington University School of Medicine, 660 S. Euclid Avenue, St Louis, MO 63110, USA.

\section{Authors' contributions}

KN and SB conceived and drafted the manuscript. All authors participated in critical revision of the manuscript. All authors read and approved the final manuscript.

\section{Competing interests}

The authors declare that they have no competing interests.

Received: 19 February 2012 Accepted: 2 April 2012

Published: 2 April 2012

\section{References}

1. Vira MA, Novakovic KR, Pinto PA, Linehan WM: Genetic basis of kidney cancer: a model for developing molecular-targeted therapies. BJU Int 2007, 99:1223-1229.

2. Dulabon LM, Lowrance WT, Russo P, Huang WC: Trends in renal tumor surgery delivery within the United States. Cancer 2010, 116:2316-2321.

3. Ficarra V, Bhayani S, Porter J, Buffi N, Lee R, Cestari A, Mottrie A: Predictors of warm ischemia time and perioperative complications in a multicenter, international series of robot-assisted partial nephrectomy. Eur Urol 2012, 61:395-402.

4. Castillo OA, Rodriquez-Carlin A, Lopez-Fontana G, Vidal-Mora I, Gomez IR: Robotic Partial nephrectomy: An initial experience in 25 consecutive cases. Actas Urol Esp 2012, 36:15-20.

5. Dulabon LM, Kaouk JH, Haber GP, Berkman DS, Rogers CG, Petros F, Bhayani SB, Stifelman MD: Multi-institutional analysis of robotic partial nephrectomy for hilar versus nonhilar lesions in 446 consecutive cases. Eur Urol 2011, 59:325-330.

6. Naeem N, Petros F, Sukumar S, Patel M, Bhandari A, Kaul S, Menon M, Rogers C: Robot-assisted partial nephrectomy in obese patients. J Endourol 2011, 25:101-105.

7. Kaouk JH, Hillyer SP, Autorino R, Haber GP, Gao T, Altunrende F, Khanna R, Spana G, White MA, Laydner $H$, et al: 252 robotic partial nephrectomies: evolving renorrhaphy technique and surgical outcomes at a single institution. Urology 2011, 78:1338-1344.

8. Lorenzo El, Jeong W, Oh CK, Chung BH, Choi YD, Rha KH: Robotics applied in laparoscopic kidney surgery: the Yonsei University experience of 127 cases. Urology 2011, 77:114-118.

9. Williams SB, Kacker R, Alemozaffar M, Francisco IS, Mechaber J, Wagner AA: Robotic partial nephrectomy versus laparoscopic partial nephrectomy: a single laparoscopic trained surgeon's experience in the development of a robotic partial nephrectomy program. World journal of urology 2011, DOI: 10.1007/s00345-011-0648-5.

10. Petros FG, Patel MN, Kheterpal E, Siddiqui S, Ross J, Bhandari A, Diaz M, Menon M, Rogers CG: Robotic partial nephrectomy in the setting of prior abdominal surgery. BJU Int 2011, 108:413-419.

11. Gong Y, Du C, Josephson DY, Wilson TG, Nelson R: Four-arm robotic partial nephrectomy for complex renal cell carcinoma. World J Urol 2010, 28:111-115.

12. Patel MN, Krane LS, Bhandari A, Laungani RG, Shrivastava A, Siddiqui $S A$, Menon M, Rogers CG: Robotic partial nephrectomy for renal tumors larger than $4 \mathrm{~cm}$. Eur Urol 2010, 57:310-316.

13. Benway BM, Bhayani SB, Rogers CG, Porter JR, Buffi NM, Figenshau RS, Mottrie A: Robot-assisted partial nephrectomy: an international experience. Eur Urol 2010, 57:815-820.

14. Scoll BJ, Uzzo RG, Chen DY, Boorjian SA, Kutikov A, Manley BJ, Viterbo R: Robot-assisted partial nephrectomy: a large single-institutional experience. Urology 2010, 75:1328-1334.

15. Benway BM, Wang AJ, Cabello JM, Bhayani SB: Robotic partial nephrectomy with sliding-clip renorrhaphy: technique and outcomes. Eur Urol 2009, 55:592-599.

16. Benway BM, Bhayani SB, Rogers CG, Dulabon LM, Patel MN, Lipkin M, Wang AJ, Stifelman MD: Robot assisted partial nephrectomy versus laparoscopic partial nephrectomy for renal tumors: a multi-institutional analysis of perioperative outcomes. J Urol 2009, 182:866-872.
17. Ho H, Schwentner C, Neururer R, Steiner H, Bartsch G, Peschel R: Roboticassisted laparoscopic partial nephrectomy: surgical technique and clinical outcomes at 1 year. BJU Int 2009, 103:663-668.

18. Benway BM, Bhayani SB: Surgical outcomes of robot-assisted partial nephrectomy. BJU Int 2011, 108:955-961.

19. Gettman MT, Blute ML, Chow GK, Neururer R, Bartsch G, Peschel R: Roboticassisted laparoscopic partial nephrectomy: technique and initial clinical experience with DaVinci robotic system. Urology 2004, 64:914-918.

20. Ramadan SU, Yigit H, Gokharman D, Tuncbilek I, Dolgun NA, Kosar P, Kosar U: Can renal dimensions and the main renal artery diameter indicate the presence of an accessory renal artery? A 64-slice CT study. Diagn Interv Radiol 2011, 17:266-271.

21. Simhan J, Smaldone MC, Tsai KJ, Canter DJ, Li T, Kutikov A, Viterbo R, Chen DY, Greenberg RE, Uzzo RG: Objective measures of renal mass anatomic complexity predict rates of major complications following partial nephrectomy. Eur Urol 2011, 60:724-730.

22. Hyams ES, Perlmutter M, Stifelman MD: A prospective evaluation of the utility of laparoscopic Doppler technology during minimally invasive partial nephrectomy. Urology 2011, 77:617-620.

23. Tobis S, Knopf J, Silvers C, Yao J, Rashid H, Wu G, Golijanin D: Near infrared fluorescence imaging with robotic assisted laparoscopic partial nephrectomy: initial clinical experience for renal cortical tumors. J Urol 2011, 186:47-52.

24. Neudecker J, Sauerland S, Neugebauer E, Bergamaschi R, Bonjer HJ, Cuschieri A, Fuchs KH, Jacobi C, Jansen FW, Koivusalo AM, et al: The European Association for Endoscopic Surgery clinical practice guideline on the pneumoperitoneum for laparoscopic surgery. Surg Endosc 2002, 16:1121-1143.

25. Weld KJ, Ames CD, Landman J, Morrissey K, Connor T, Hruby G, Allaf ME, Bhayani SB: Evaluation of intra-abdominal pressures and gas embolism during laparoscopic partial nephrectomy in a porcine model. J Urol 2005, 174:1457-1459.

26. Richstone L, Seideman C, Baldinger L, Permpongkosol S, Jarrett TW, Su LM, Pavlovich C, Kavoussi LR: Conversion during laparoscopic surgery: frequency, indications and risk factors. J Urol 2008, 180:855-859.

27. Galvin DJ, Savage CJ, Adamy A, Kaag M, O'Brien MF, Kallingal G, Russo P. Intraoperative conversion from partial to radical nephrectomy at a single institution from 2003 to 2008. J Urol 2011, 185:1204-1209.

doi:10.1186/1754-9493-6-8

Cite this article as: Nepple et al: Description of a multicenter safety checklist for intraoperative hemorrhage control while clamped during robotic partial nephrectomy. Patient Safety in Surgery 2012 6:8.

\section{Submit your next manuscript to BioMed Central and take full advantage of:}

- Convenient online submission

- Thorough peer review

- No space constraints or color figure charges

- Immediate publication on acceptance

- Inclusion in PubMed, CAS, Scopus and Google Scholar

- Research which is freely available for redistribution 